\title{
Pyrene Nanocrystals Crystallized by a Continuous Flow Microreactor
}

\author{
Norihito Doki*, Masaaki Yokota \\ Department of Chemistry and Biological Sciences, Faculty of Science and Engineering, Iwate University, Morioka, Japan \\ Email: *doki@iwate-u.ac.jp
}

How to cite this paper: Doki, N. and Yokota, M. (2021) Pyrene Nanocrystals Crystallized by a Continuous Flow Microreactor. Journal of Materials Science and Chemical Engineering, 9, 1-6. https://doi.org/10.4236/msce.2021.911001

Received: October 5, 2021

Accepted: November 14, 2021

Published: November 17, 2021

Copyright (c) 2021 by author(s) and Scientific Research Publishing Inc. This work is licensed under the Creative Commons Attribution International License (CC BY 4.0).

http://creativecommons.org/licenses/by/4.0/ (c) (i) Open Access

\begin{abstract}
Pyrene solution and distilled water were flowed through a microreactor at a predetermined flow rate to generate pyrene crystals. Pyrene nanocrystals were crystallized by a Continuous Flow Microreactor. The particle size and luminescence properties of pyrene nanocrystals produced were evaluated. The crystal mean size between $60 \mathrm{~nm}$ and $400 \mathrm{~nm}$ could be controlled by the operating conditions. The crystal mean size decreased with increasing flow rate and solution concentration. In addition, the crystal morphology also changed. In the case of slow flow conditions, a needle-like crystal morphology was obtained. The crystal morphology became spherical on increasing the flow rate. Pyrene crystals with size about $400 \mathrm{~nm}$ exhibited luminescence at about 470 $\mathrm{nm}$. As the crystal size decreased, the intensity of the luminescence also declined. The luminescence wavelength was in the range of about 370 to 400 $\mathrm{nm}$.
\end{abstract}

\section{Keywords}

Crystal Size, Pyrene Nanocrystals, Continuous Process

\section{Introduction}

The size-dependent luminescence properties of inorganic nanocrystals have often been studied. The luminescence colors were found to depend on the particle size, while the luminescence wavelength was reported to shift to short-wavelength as the particle size was decreased (quantum size effect). Nanocrystals displaying high fluorescence intensity and stability are used as monochromatic, ultraviolet light-emitting materials or display materials. In the case of organic nanoparticles, significant size effects generally cannot be considered because of the delocalization of the electrons in individual molecules over whole grains owing to weak interactions. However, $\pi$-conjugated polymer nanoparticles and a variety 
of dye molecules have been reported to exhibit a variety of optoelectronic properties. For example, the luminescence of perylene nanocrystals with size of 100 $\mathrm{nm}$ was reported to be dependent on the crystal size. Analogous absorption and fluorescence spectral changes have also been reported for inorganic nanocrystals. However, these apparently size-dependent optical phenomena are not directly attributed to changes in the crystal size and electronic state. In fact, a reduction of the crystal size is advantageous for surface phenomena with consequent impact on the overall electronic state of the molecules. Therefore, in order to clarify the principles underlying the size dependence of the optical properties, it is necessary to generate monodisperse nanocrystals [1]-[6].

In this study, pyrene (pseudonym: benzo(d,e,f)phenanthrene), having high luminous efficiency and a rigid structure with a two-dimensional extended aromatic ring, was used as model material. An efficient method for continuous production of monodisperse crystals utilizing a reactor is presented, and the size- and shape-dependent luminescence properties of the crystals are evaluated.

\section{Experimental}

Pyrene was dissolved in ethanol, and the solution was adjusted to $20 \mathrm{ml}$. Pyrene solution and distilled water is set to a predetermined flow rate for each set, and their solutions were flowed by High Performance Liquid Chromatography (HPLC) pump (Shimadzu LC-20AT). The solutions were mixed in a microreactor. The liquid feed flow path and put in incubator ultrasonic reactor under oscillating frequency of $40 \mathrm{kHz}$, the crystals produced for 20 minutes and the suspended solution was sampled. Then the producing crystals were dried in a vacuum desiccators and they were evaluated by Dynamic Light Scattering measurement (ELS-800), Transmission Electron Microscope (TEM (H-800)), powder XRD (RINT2200) and Fluorescence spectra (JASCOFP-6500). Figure 1 shows the experimental apparatus.

\section{Results and Discussion}

Figure 2 shows the crystal size distributions obtained using various pyrene concentrations and flow ratios. Table 1 shows the mean crystal size. The crystal size decreased with increasing pyrene concentration and increasing flow rate. Increasing the solution concentration increased the supersaturation during particle formation. In addition, increasing the flow rate of the feed is also related to an increased rate of supersaturation generation. For a pyrene concentration of 20 $\mathrm{mM}$, the average particle size was $60 \mathrm{~nm}$. The concentrations of the suspensions were between $9.1 \times 10^{-4}$ and $1.8 \times 10^{-3}(\mathrm{~mol} / \mathrm{l})$. The coefficient of variation (C.V.) of the crystal-size distributions was approximately $20 \%$. The morphology of the crystals was evaluated using transmission electron microscopy (TEM) and powder X-ray diffraction (PXRD). Figure 3 shows TEM images of the crystals obtained using a $20 \mathrm{mM}$ pyrene solution while varying the flow rate. In the case 


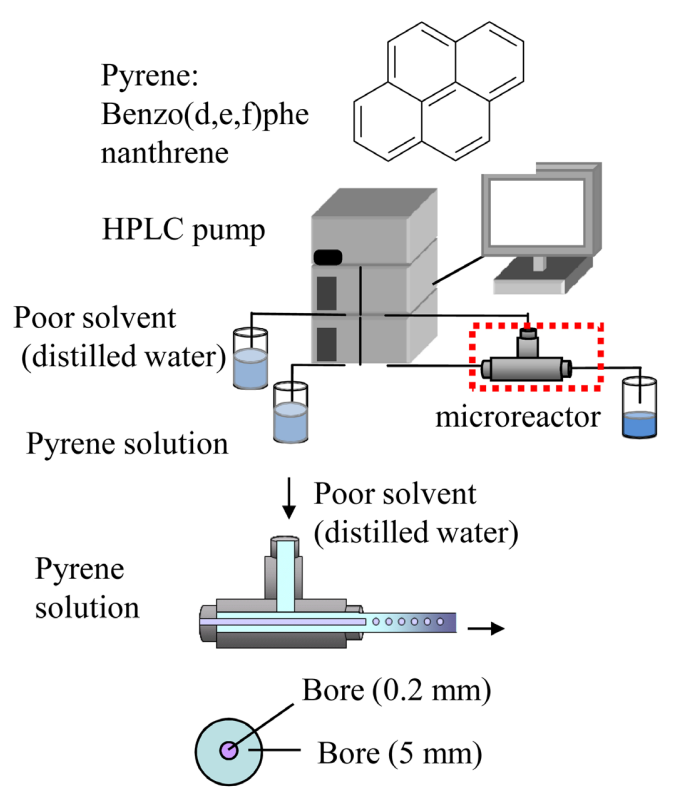

Figure 1. Schematic diagram of experimental apparatus and microreactor.

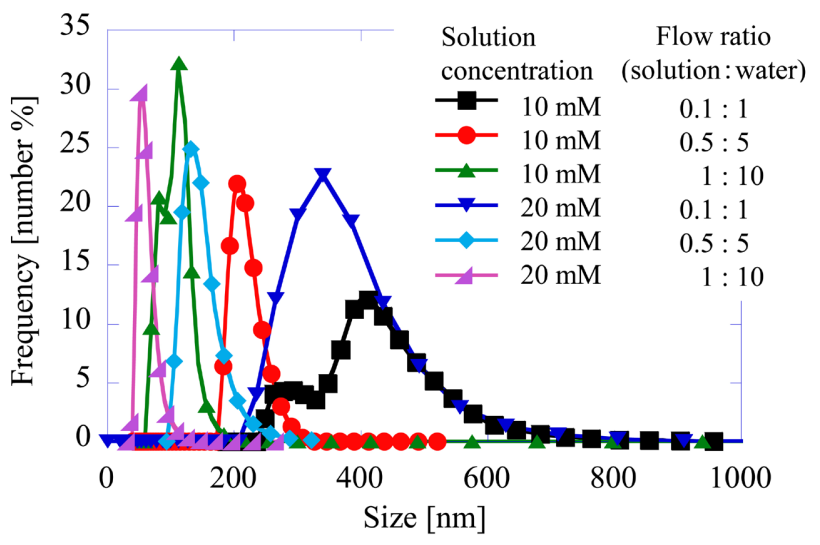

Figure 2. Crystal size distribution of products.

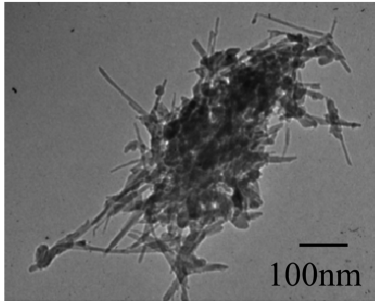

Flow ratio $[\mathrm{ml} / \mathrm{min}]$

(solution:water)

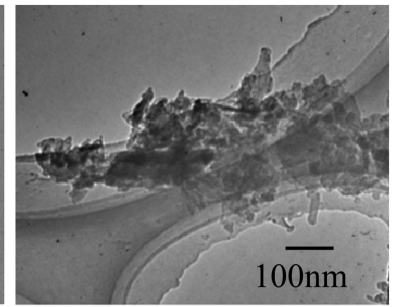

$0.5: 5$

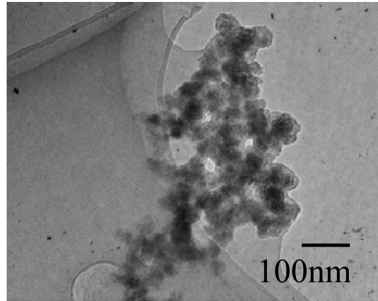

$1: 10$

Figure 3. Transmission electron microscopy photograph of products generated under different flow ratios (solution concentration: $20[\mathrm{mM}]$ ).

of slow flow conditions, a needle-like crystal morphology was obtained. The crystal morphology became spherical on increasing the flow rate. Figure 4 shows the PXRD patterns of the products obtained under various flow rate conditions. 


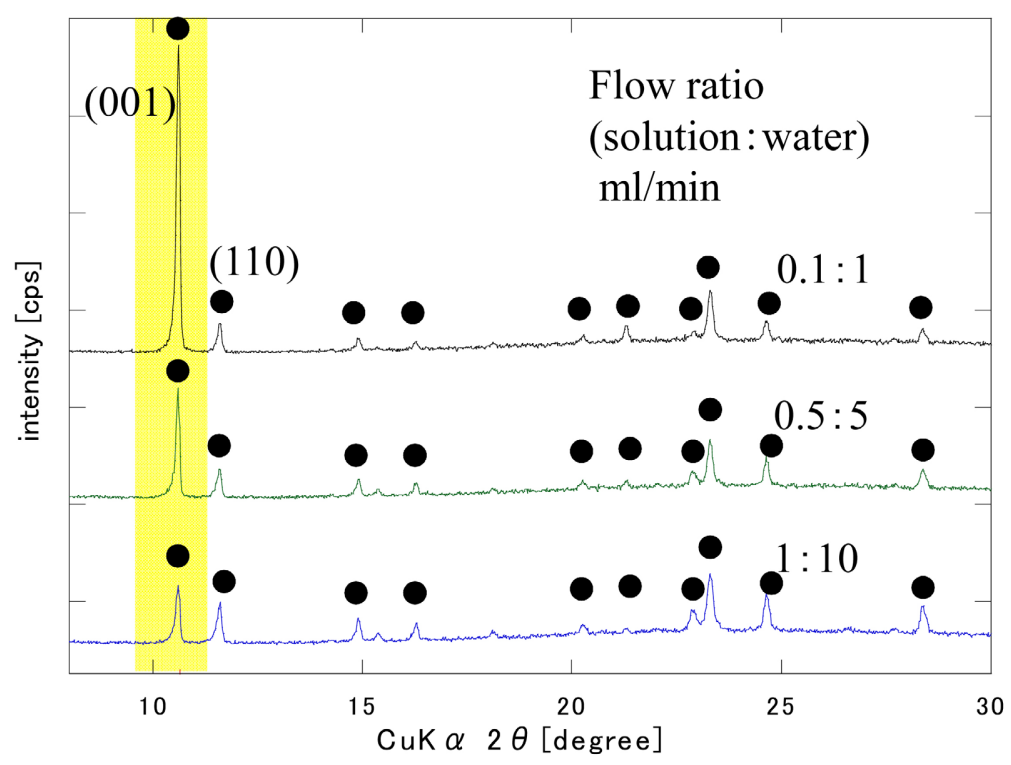

Figure 4. Powder X-ray diffraction patterns of products under different flow ratios of solution with concentration $20 \mathrm{mM}$.

Table 1. Mean size of products.

\begin{tabular}{ccc}
\hline $\begin{array}{c}\text { solution concentration } \\
{[\mathrm{mM}]}\end{array}$ & $\begin{array}{c}\text { flow rate }[\mathrm{ml} / \mathrm{min}] \\
\text { solution:water }\end{array}$ & mean size $[\mathrm{nm}]$ \\
\hline 10 & $0.1: 1$ & 411 \\
10 & $0.5: 5$ & 205 \\
10 & $1: 10$ & 112 \\
20 & $0.1: 1$ & 367 \\
20 & $0.5: 5$ & 131 \\
20 & $1: 10$ & 60 \\
\hline
\end{tabular}

As the flow rate increased, the crystal size also decreased. The PXRD results demonstrate that the intensity of the (001) reflection decreased with increasing flow rate. Small pyrene crystals have a very large surface area ratio; thus, the crystal shape is governed by the surface free energy. The crystal shape becomes spherical with minimum surface area, whereas the crystals adopt a needle-like morphology with increasing crystal size. Pyrene crystals exhibit a tendency to stabilize by forming needle-like structure with growth. The fluorescence spectrum of the product crystals was acquired under $340 \mathrm{~nm}$ excitation, as shown in Figure 5. The fluorescence spectrum varied with the differences in crystal size. Crystals with an average size of about $370 \mathrm{~nm}$ exhibited emission about at 470 $\mathrm{nm}$ only. Moreover, the intensity of this peak declined as the crystal size decreased. As the crystal size further decreased, an additional luminescence peak with two maxima about at 370 and $400 \mathrm{~nm}$ was observed. The spectral profile of this luminescence peak was similar to that of $0.1 \mathrm{mM}$ pyrene solution. When the average crystal size was $60 \mathrm{~nm}$, the luminescence peak about at $470 \mathrm{~nm}$ was 


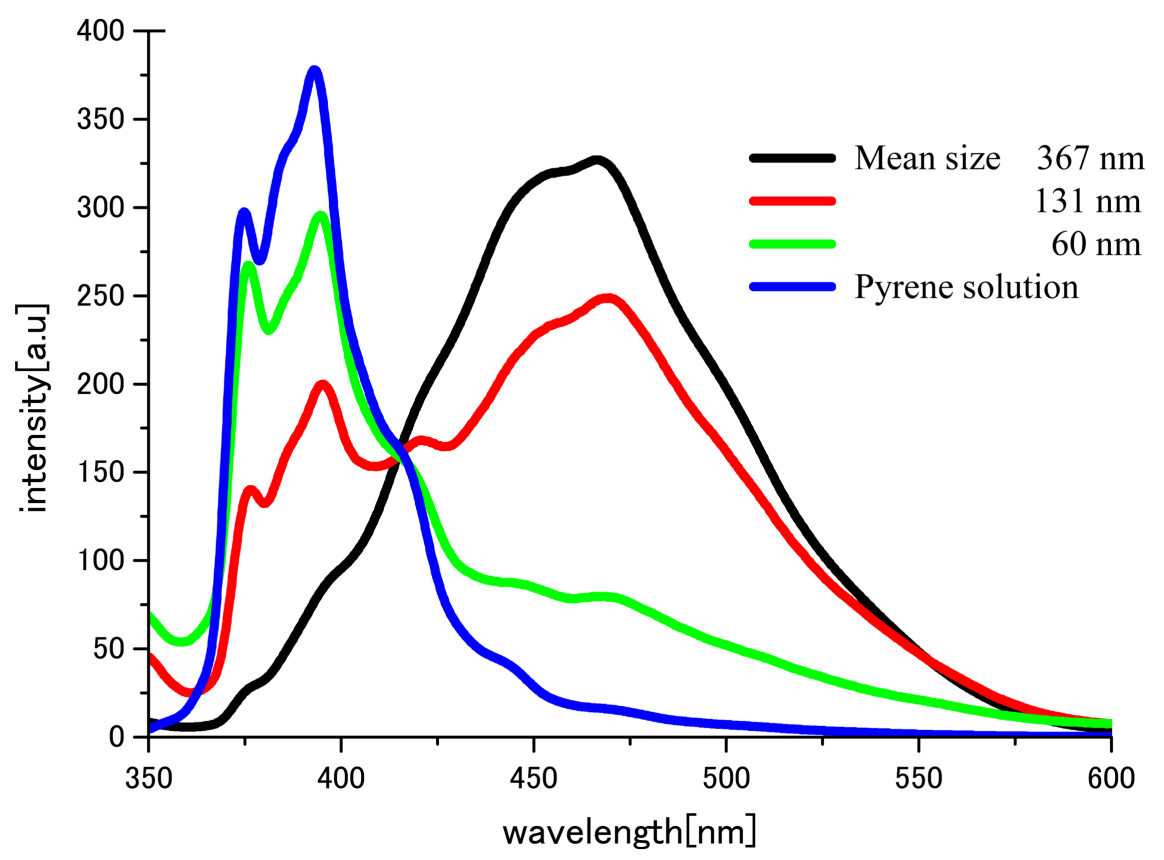

Figure 5. Fluorescence spectra of products produced by different flow ratio under pyrene solution $20 \mathrm{mM}\left(\lambda_{\mathrm{ex}}=340 \mathrm{~nm}\right)$.

not observed. The excited molecule may collide with a ground state pyrene molecule nearby, thus forming a low-energy excimer. Consequent lattice deformations caused by $\pi$ stacking of the pyrene molecules result in the reorganization of the energy states for stabilization. There is a critical crystal size required for excimer transition. In other words, it is suggested that the critical crystal size is sufficient for the luminescence energy monomer. The excimer fluorescence intensity is proportional to the number of pyrene molecule collisions. Decreasing the crystal size leads to an increased number of molecules inside the molecule than present on the surface. The lack of expression of excimer luminescence is thus attributed to the reduced number of pyrene molecules colliding.

\section{Conclusion}

The crystal mean size between $60 \mathrm{~nm}$ and $400 \mathrm{~nm}$ could be controlled by the operating conditions. The crystal mean size decreased with increasing flow rate and solution concentration. In addition, the crystal morphology also changed. In the case of slow flow conditions, a needle-like crystal morphology was obtained. The crystal morphology became spherical on increasing the flow rate. Pyrene crystals with size of about $400 \mathrm{~nm}$ exhibited luminescence at about $470 \mathrm{~nm}$. As the crystal size decreased, the intensity of the luminescence also declined. The luminescence wavelength was in the range of about 370 to $400 \mathrm{~nm}$.

\section{Conflicts of Interest}

The authors declare no conflicts of interest regarding the publication of this paper. 


\section{References}

[1] Lee, Y.-J., Sounart T.L.,, Liu, J., Spoerke, E.D., McKenzie, B.B., Hsu, J.W.P. and Voigt, J.A. (2008) Tunable Arrays of ZnONanorods and Nanoneedles via Seed Layer and Solution Chemistry. Crystal Growth \& Design, 8, 2036-2040. https://doi.org/10.1021/cg800052p

[2] Zhou, X., Hu, Z., Fan, Y., Chen, S., Ding, W. and Xu, N. (2008) Microspheric Organization of Multilayered $\mathrm{ZnO}$ Nanosheets with Hierarchically Porous Structures. Journal of Physical Chemistry C, 112, 11722-11728.

https://doi.org/10.1021/jp802619j

[3] Zhang, X., Zhang, X., Shi, W., Meng, X., Lee, C. and Lee, S. (2005) Morphology-Controllable Synthesis of Pyrene Nanostructures and Its Morphology Dependence of Optical Properties. Journal of Physical Chemistry B, 109, 18777-18780. https://doi.org/10.1021/jp052385j

[4] Inoguchi, M., Suzuki, K., Kageyama, K., Takagi, H. and Sakabe, Y. (2008) Monodispersed and Well-Crystallized Zinc Oxide Nanoparticles Fabricated by Microemulsion Method. Journal of the American Ceramic Society, 91, 3850-3855. https://doi.org/10.1111/j.1551-2916.2008.02745.x

[5] Ndosiri, B.N., Nfor, E.N., Marrot, J., Mohamadou, A. and Nenwa, J. (2020) Ni(II) N-(2-Pyridylmethyl)-L-alanine) Complex: Structural Diversity and Photoluminiscent Studies. Crystal Structure Theory and Applications, 9, 63-72. https://doi.org/10.4236/csta.2020.94006

[6] Zhang, R., Wang, X., Zhang, Y. and Liu, T. (2019) Real-Time Characterization of Crystal Shape and Size Distribution Based on Moving Window and 3D Imaging in a Stirred Tank. Journal of Crystallization Process and Technology, 9, 13-38. https://doi.org/10.4236/jcpt.2019.92002 